\title{
ULTRASONOGRAPHIC ESTIMATION OF THYROID GLAND VOLUME IN HEALTHY SUBJECTS OF INTERIOR SINDH (PROVINCE OF PAKISTAN).
}

\author{
1. MBBS, FCPS, MS \\ Assistant Professor \\ Department of Diagnostic Radiology \\ Peoples University of Medical \& \\ Health Scinces for Women Shaheed \\ Benazir Abad \\ (PUMHSW.SBA). \\ 2. MBBS \\ Senior Registrar \\ Suleman Roshan Medical College \\ Tando Adam
}

Correspondence Address:

Dr. Jawad Ali Memon

House No.130, Farsi Bagh,

Nawabshah.

jawadnimra@yahoo.com

Article received on:

25/09/2018

Accepted for publication:

$13 / 03 / 2019$

\begin{abstract}
Jawad Ali Memon', Abdul Rasheed ${ }^{2}$
ABSTRACT: Ultrasonography is the most common \& easy method to estimate the thyroid gland volume. There is wide variation in the volume of the thyroid gland in normal individuals of different ages, sex, races \& geography location. Objectives: To estimate the ultrasonographic thyroid gland volume \& its reference range in healthy volunteers of interior Sindh, province of Pakistan. Study Design: Cross Sectional Prospective study. Setting: Conducted in Department of Radiology of PUMHS Nawabshah. Period: From 15 August 2017 to 15 February 2018. Material \& Methods: Total 102 healthy subjects were included. The subjects having history of any thyroid disease or surgery, systematic disease, iodine deficiency or taking any drug were excluded. Every subject's thyroid ultrasound was performed by experienced radiologist \& thyroid gland volume of each lobe was calculated. Results: The mean total thyroid gland volume of all study subjects was $9.14+2.97 \mathrm{~cm}^{3}$. The mean volume of right lobe is significantly larger than that of left lobe $(5.27+3.82$ vs $3.82+1.41, p<0.005)$. The mean thyroid volume of the male subjects was larger than in the females $\left(11.67+3.06\right.$ vs $\left.8.50+2.87 \mathrm{~cm}^{3}\right)$, the difference between both sexes was statistically significant $(p<0.005)$ (Table-l). There was no statistically correlation was found between thyroid gland volume with body mass index $((p<0.005)$. Conclusion: We tried to contribute to establish the reference values for our local population and further large studies are required to establish national wide reference values of thyroid gland volume.
\end{abstract}

Key words: $\quad$ Thyroid Gland, Ultrasound, Volume.

Article Citation: Memon JA, Rasheed A. Ultrasonographic estimation of Thyroid gland volume in healthy subjects of interior Sindh (Province of Pakistan). Professional Med J 2020; 27(1):201-204. DOI: 10.29309/TPMJ/2020.27.1.4405

\section{INTRODUCTION}

Thyroid gland is the largest \& highly vascular endocrine gland situated in anterior lower neck. Majority of cases consists of two lobes connected by the isthmus and in some cases accessory lobe is noted. There is wide variation in the morphology of anatomical features like the size, shape, accessory lobes, volume and weight of the thyroid gland in normal individuals of different ages, sex, races \& geography location. ${ }^{1-5}$

There are various methods available to estimate thyroid size and volume. These include palpation, ultrasonography, radionuclide study, and computed tomography in live individuals \& by post mortem dissection in cadavers. ${ }^{6,7,8}$ Each method has its own advantages \& disadvantages, ultrasonography examination is preferred due to wide availability, low cost, without radiation risk \& easy to perform. ${ }^{9,10}$
Although large numbers of studies have assessed thyroid gland volume by ultrasound in healthy subjects in different parts of world ${ }^{11-14}$, no study is yet reported in our region. This study aims to estimate thyroid gland volume by ultrasound in healthy subjects of the interior Sindh, province of Pakistan.

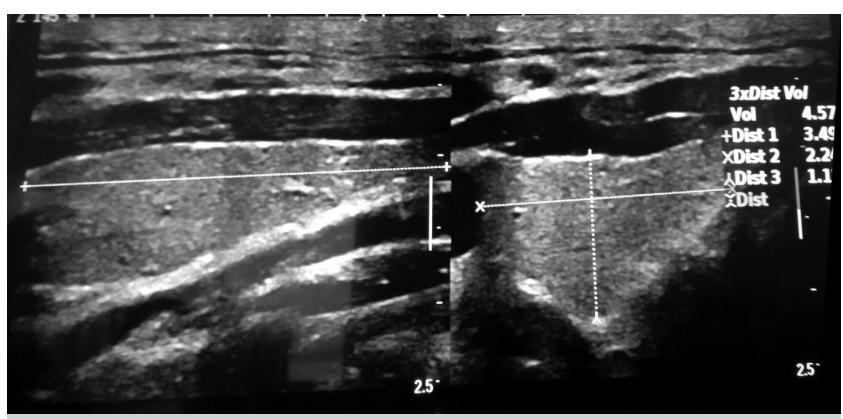

Figure-1. Ultrasound measurement of thyroid gland volume

a. Longitudinal section b. Transverse section 


\section{MATERIALS \& METHODS}

After approval of ethical committee, this prospective cross sectional study is conducted in department of radiology of Peoples University of Medical \& Health Science for Women Shaheed Benazirabad (PUMHSW.SBA) from 15 August 2017 to 15 February 2018. Total of 102 healthy volunteers including both men \& women having normal TSH \& urine iodine levels, included in the study through purposive random sampling. The subjects having history of any thyroid disease or surgery, systematic disease, taking any drug are excluded. After taking informed consent, every volunteer is evaluated through detailed history \& clinical examination. The demographic characteristics like age, sex, height \& weight of the each study subject are recorded through the proforma.

Ultrasonography of the thyroid gland is performed through ultrasound system Toshiba Nemio using $12 \mathrm{MHz}$ transducer by qualified radiologist having experience of more than five years. The ultrasound of the subjects is performed in supine position with neck extended. Longitudinal \& transverse views of the thyroid gland are acquired (Figure-1) \& volume of each lobe is calculated by using formula:

Volume $(\mathrm{ccm})=$ Width $(\mathrm{cm}) \times$ Length $(\mathrm{cm}) \times$ Depth $(\mathrm{cm}) \times 0.479$.

The thyroid volume is estimated by the sum of the volumes of both lobes. The volume of the isthmus was not included.

The data was collected \& analysed using SPSS 10. The total \& each lobe of thyroid gland volume is represented by mean + standard deviation. The comparisons between volume of right \& left thyroid lobe, and of both sexes were analyzed by Student T test. Pearson's correlation coefficient was used to relate thyroid gland volume to body mass index in both sexes. $P$ value $<0.05$ was considered significant.

\section{RESULTS}

Out of 102 subjects, 55 were male \& 47 females. The mean age of the study subjects was $32.12+5.18$ years, with range between 20 to 44 years. The mean total thyroid gland volume of all study subjects was $9.14+2.97 \mathrm{~cm}^{3}$. The mean volume of right lobe is significantly larger than that of left lobe $(5.27+3.82$ vs $3.82+1.41, p<0.005)$. The mean thyroid volume of the male subjects was larger than in the females $(11.67+3.06$ vs $\left.8.50+2.87 \mathrm{~cm}^{3}\right)$, the difference between both sexes was statistically significant $(p<0.005)$ (table 1).There was no statistically correlation was found between thyroid gland volume with body mass index $((p<0.005)$.

\begin{tabular}{|l|c|}
\hline \multicolumn{1}{|c|}{ Subjects (number) } & Mean ThyroidVolume $\mathbf{( c m}^{\mathbf{3}} \mathbf{)}$ \\
\hline Total (102) & $9.14+2.97$ \\
\hline Males (55) & $11.67+3.06$ \\
\hline Females (47) & $8.50+2.87$ \\
\hline Right lobe & $5.27+3.82$ \\
\hline Left lobe & $3.82+1.41$ \\
\hline \multicolumn{2}{|c|}{ Table-l. Total thyroid gland \& its lobe volume in all } \\
study subjects
\end{tabular}

\section{DISCUSSION}

lodine deficiency is an important public health problem and is the foremost preventable cause of morbidity \& mortality worldwide. ${ }^{15}$ The most apparent manifestation of iodine deficiency is goiter, an enlargement of the thyroid gland. This enlargement is estimated by palpation, weight \& volume of thyroid gland. The palpation procedure was approved by WHO as accurate method of diagnoses of endemic goiter. Due to large intra \& inter observer errors and imprecise assessment by the palpation, the ultrasonography is now preferred to evaluate the thyroid gland. ${ }^{16}$ The ultrasound can calculate accurately both the volume \& weight of the whole thyroid gland \& its individual lobe.

Ultrasonographic assessment of thyroid gland size is done in large number of studies \& has provided reference range of thyroid gland volume \& weight in normal subjects. ${ }^{17,18}$ Due to wide variation in the size, volume and weight of the thyroid gland in normal individuals of different age, sex, races \& geography location ${ }^{1-5}$, these reference range values provided for the different population cannot be compared to specific study group..$^{19,20}$ 
This is first study evaluating the thyroid gland size in healthy subjects of interior Sindh, province of Pakistan \& provides the reference range of thyroid gland volume. There is no local study yet reported for comparison in our country.

The mean whole thyroid gland volume of our study subjects is $9.14+2.97 \mathrm{~cm}^{3}$. It is almost comparable with that of Iran $\left(9.53 \pm 3.68 \mathrm{~cm}^{3}\right)$ but lower than that of Turkish population (12.98 \pm 2.53 $\left.\mathrm{cm}^{3}\right) .{ }^{21,22}$ The mean thyroid gland volume of our study subjects is larger than that of Chinese \& African countries. This difference may be due to different age range, geographical location and body mass index of the study subjects.

This study show right thyroid lobe volume is significantly larger than that of left lobe $(5.27+3.82$ vs $3.82+1.41, p<0.005)$. This finding is in accordance with previous studies done among the Turkish, Africans and the Chinese population. ${ }^{22-24}$

The mean thyroid volume of the male subjects is larger than in the females $(11.67+3.06$ vs $\left.8.50+2.87 \mathrm{~cm}^{3}, \mathrm{p}<0.005\right)$, as noted by the other investigators.

\section{CONCLUSIONS}

We have present values of thyroid gland volumes in adult healthy subjects of interior Sindh, province of Pakistan assessed by ultrasonography. The mean volume of the whole thyroid gland in the study subjects is $9.14+2.97 \mathrm{~cm}^{3}$. The thyroid gland volume is larger in male than females \& right lobe of thyroid gland is larger than left lobe in both sexes. Though our sample size is limited, we tried to contribute to establish the reference values for our local population and further large studies are required to establish national wide reference values of thyroid gland volume.

Copyright@ 13 Mar, 2019.

\section{REFERENCES}

1. Strachan MWJ, Walker BR. Endocrine disease. In: Boon NA, Colledge NR, Walker BR, Hunter JAA, eds. Davidson's Principles and Practice of Medicine, $20^{\text {th }}$ ed. New Delhi: Elsevier Churchill Livingstone; 2006: 744762.
2. Veerahanumaiah S, Dakshayani KR, Menasinkai SB. Morphological variations of the thyroid gland. Int $\mathrm{J}$ Res Med Sci. 2015; 3(1): 53-57, doi:10.5455/2320-6012. ijrms20150110.

3. Pastor VJ, Gill Vj, De Paz Fernandez Fj, Cachorro MB. Agenesis of the thyroid isthmus. Eur J Anat. 2006; 10:83-4.

4. Gangbo E, Lacombe D, Alberti EM, Tainee L, Saura R, Carles D. Trisomy 22 with thyroid isthmus agenesis and absent gall bladder. Genet Couns. 2004; 15:311-5.

5. Kaur HS, Kumar U, Bajwa, SJS, Kalyan GS. Absent Thyroid embryological and clinical implications of rare variations of thyroid gland revisited. Thyroid Res Pract. 2013; 10:80-2.7.

6. Shilpa MB, Harsh MP, Ravishankar MV. Agenesis of isthmus of thyroid gland in adult human cadavers; $A$ case series. Cases J. 2009; 2:6640.

7. Kollorz EK, Hahn DA, Linke R, Goecke TW, Hornegger J, Kuwert T. Quantification of thyroid volume using 3-D ultrasound imaging. IEEE Trans Med Imaging 2008; 27:457-466.

8. Ying $M$, Young DM, Ho KK. Two-dimensional ultrasound measurement of thyroid gland volume; a new equation with higher correlation with 3-D ultrasound measurement. Ultrasound Med Biol 2008; 34:56-63.

9. Brahmbhatt SR, Brahmbhatt RM, Boyages SC. Thyroid ultrasound is the best prevalence indicator for assessment of iodine deficiency disorders: A study in rural/tribal schoolchildren from Gujarat (Western India) European Journal of Endocrinology. 2000; 143(1):37-46.

10. Peterson S, Sanga A, Eklöf $H$, et al. Classification of thyroid size by palpation and ultrasonography in field surveys. Lancet. 2000; 355(9198):106-110.

11. Harjeet A1, Sahni D, Jit I, Aggarwal AK. Shape, measurement and weight of the thyroid gland in northwest Indians. Surg Radiol Anat. 2004 Apr; 26(2):91-5.

12. Fakhrul AH, Zakia S, Mansur K, Seheli ZS, Sheikh MAB, Abdul Q, Fashiru R (2010) Weight and volume of whole thyroid gland in Bangladesh people: A postmortem study. Bangladesh J Anat, 8: 72-75.

13. Ying M1, Yung Dm. Asymmetry of thyroid lobe volume in normal Chinese subjects: Association with handedness and position of esophagus. Anat Rec (Hoboken). 2009 Feb; 292(2):167-74. 
14. Maryam Moradi, Mahin Hashemipour, Shirin Akbari, Zahra Kor, Sayed Ali Mirbod, Mohammad Reza Kooshanmehr. Ultrasonographic evaluation of the thyroid gland volume among 8-15-year-old children in Isfahan, Iran. Adv Biomed Res. 2014; 3:9.

15. WHO/ICCIDD. Assessment of lodine Deficiency Disorders and Monitoring Their Elimination: A guide for program managers. WHO/NHD/01-1, Geneva, Switzerland, 2001.

16. Zimmermann MB, Hess SY, Molinari L, De Benoist B, Delange F, Braverman LE et al. New reference values for thyroid volume by ultrasound in iodine-sufficient schoolchildren: A World Health Organization/ Nutrition for Health and Development lodine Deficiency Study Group Report. Am J Clin Nutr. 2004; 79:231-7.

17. Xu F, Sullivan K, Houston R, Zhao J, May W, Maberly G. Thyroid volumes in US and Bangladeshi schoolchildren: Comparison with European schoolchildren. Eur J Endocrinol. 1999; 140:498-504.

18. Berghout A, Wiersinga WM, Smits NJ, Touber JL. Determinants of thyroid volume as measured by ultrasonography in healthy adults in a non-iodine deficient area. Clin Endocrinol (Oxf) 1987; 26:273-80.

19. Foo LC, Zulfiqar A, Nafikudin M, Fadzil MT, Asmah AS. Local versus WHO/International council for control of iodine deficiency disorders-recommended thyroid volume reference in the assessment of iodine deficiency disorders. Eur J Endocrinol. 1999; 140:491-7.
20. Kim BK, Choi YS, Oak CH, Park YH, Kim JH, Park DJ, et al. Determination of thyroid volume by ultrasonography among schoolchildren in Philippines. Int J Endocrinol 2012. 2012387971.

21. Adibi A., Sirous M., Aminorroaya A., Roohi E., Mostafvi M., Fallah Z., Tabatabaeia A., Amini M. Normal values of thyroid gland in Isfahan, an iodine replete area. JRMS 2008; 13(2): 55-60.

22. Sahin E, Elboğa2 U, Kalender E. "Regional reference values of thyroid gland volume in Turkish adults" Srp Arh Celok Lek. 2015 Mar-Apr; 143(3-4):141-5.7.

23. Hsiao YL, Chang TC. Ultrasound evaluation of thyroid abnormalities and volume in Chinese adults without palpable thyroid glands. J Formos Med Assoc. 1994; 93:140-4.

24. Yousef $M$, Sulieman A, Ahmed B, Abdella A, Eltom K. Local reference ranges of thyroid volume in Sudanese normal subjects using ultrasound. J Thyroid Res. 2011; 2011:935141.

\begin{tabular}{|c|c|c|c|}
\hline \multicolumn{3}{|c}{ AUTHORSHIP AND CONTRIBUTION DECLARATION } \\
\hline Sr. \# & Author(s) Full Name & Contribution to the paper & Author(s) Signature \\
\hline 1 & Jawad Ali Memon & Concept \& Data collection. \\
\hline 2 & Abdul Rasheed & Discussion \& Proof Reading. \\
\hline
\end{tabular}

